\title{
El futuro de la dialectología catalana
}

\author{
JOAN VENY
}

(NIVIRSIIDAD DIE BARCLLONA

\section{INTRODUCCION}

1. Es indudable que hay una serie de problemas relativos a los dialectos que son comunes a todas las áreas linguiísticas de la Romania. Básicamente, las condiciones en las que viven (y ¡mueren!) los dialectos: decadencia de la cultura popular, influencia de la lengua oficial, contacto de lenguas, etcétera. Pero estas condiciones difieren a veces si se trata de uno u otro dominio. La dialectología castellana, la dialectología de "langue d'oîl" y la dialectología catalana, para citar unos ejemplos, se enfrentan a veces con problemas específicos (por ejemplo, la participación de los grandes dialectos en la lengua estándar, como ocurre en catalán). Cada dominio lingüístico, además, ha avanzado de modo diverso en los distintos sectores de la dialectología y ha aplicado métodos de investigación de resultado vario. De ahí la presencia de un determinante en el título de mi conferencia, El futuro de la dialectología catalana.

Haré, pues, un esbozo que, en síntesis, haga ver dónde hemos llegado y hacia dónde vamos a navegar en dialectología catalana. Será interesante quetambién los dialectólogos no catalanes conozcan nuestras líneas de trabajo y nuestras inquietudes hacia el futuro*.

\section{LOS ATLAS}

2. En geolingüística, desde Gilliéron, se ha recorrido un largo camino jalonado de enriquecimientos por lo que concierne al espacio (atlas naciona-

\footnotetext{
* Este trabajo es una traducción. ampliada en algunos puntos, del que aparecerá en Quaderni di Semantica (Bologna, Italia), con el título “Où va la dialectologie'?»
} 
les, regionales, continentales, de familias lingüísticas [románica, eslava, etcétera]), la temática (atlas generales, folklóricos, marítimos), la realización de las encuestas (uso del magnetófono, cuestionario de imágenes [PLIM]), la cartografía de los materiales (mapas areológicos, de símbolos, de incidencias léxicas, adición de comentarios motivacionales), la informatización de los materiales allegados e incluso la presentación oral de los mismos (atlas parlantes; Goebl, 1992).

El catalán ha tenido el privilegio de ver cubierto su espacio lingüístico por varios atlas, sea de todo el dominio (ALC, ALDC — en curso de elaboración-, ALPI), sea de una parte de su dominio (ALF, ALAnd, ALPO). Añádanse todavía 1) la Flexió verbal de Alcover-Moll (1929-1933), recogida de las variantes de unos 70 verbos en 148 localidades de todos los países de habla catalana, que corresponden a un estado de lengua de hacia 1920, publicada en forma de listas, pero convertible fácilmente a la forma cartográfica; y 2) el Atlas Sacaze, basado en dos leyendas pirenaicas traducidas a diversas hablas norte-catalanas y occitanas y que reflejan la situación de estos dialectos hacia finales del siglo XIX.

El Atlas Lingüístic del Domini Català representará - así lo espero- un progreso notable en relación a los atlas anteriores: incremento de localidades (190), encuestas en equipo (cuyos miembros actúan como tal y no por separado), registro magnetofónico parcial, cuestionario más amplio (2.016 preguntas que, con el tratamiento informático, pasan a 2.452), carácter etnográfico, colección de etnotextos, archivo dialectal sonoro, informatización de los datos.

\section{FRONTERAS Y ÁREAS LINGÜÍSTICAS}

3. El tema de las fronteras atrajo muy pronto la atención de los investigadores. Y así vimos trazadas las fronteras con el occitano (Krüger, 1913; Salow, 1912 y Schädel, 1908) y con el aragonés o el castellano (Griera, 1914; Hadwiger, 1905 y Menéndez Pidal, 1916); en general se trata de macrofronteras que dan una visión de conjunto de las isoglosas. Este tipo de estudios se ha completado con otros de microfrontera que se ocupan más a fondo de tramos fronterizos, con un cuestionario específico aplicado a un número más alto de puntos; es el caso de la Alta Ribagorza (Haensch, 1960) y la Alta Llitera (Sistac, 1987). Ante el despoblamiento masivo de esos lugares y la creciente nivelación linguística, cabe encarecer la urgente realización de este tipo de trabajos. 
En cuanto al estudio de los límites internos, se han buscado a veces líneas de frontera (por ejemplo, Cabré, 1977): sin embargo, para dar una idea más completa y pormenorizada del paso de un dialecto a otro (o de una lengua a otra), conviene proceder a un análisis estadístico que, por medio de porcentajes según sectores lingüísticos, establece de una manera más exacta, más científica y menos impresionista, la transición entre dialectos (véase, al respecto, el estudio modélico de Daniel Recasens, 1985, sobre el "tarragoní"). Habría que aplicar un método semejante a la transición entre catalán central y rosellonés, entre tramos del catalán oriental y del catalán occidental; adviértase que la dialectometría, que ha dado resultados diversos en catalán (Sardà-Guiter, 1975 y Polanco, 1984), no es idónea a la aplicación de este método que exige un cuestionario "ad hoc".

Desde Milà i Fontanals (1861), se divide nuestro dominio en dos grandes bloques dialectales, el catalán occidental y el catalán oriental. Esta macrodivisión, como la de la Romania en oriental y occidental, se apoya en una base predominantemente diacrónica y ha pretendido justificarse a partir del substrato (Sanchis Guarner, 1956), de la romanización (Badía, 1981) o de la llamada Reconquista (Griera, 1931, Alarcos, 1960 y Ferrando, 1989); estos dos últimos - Ferrando con nueva documentación- justifican sobre todo el carácter occidental de los dialectos centromeridionales, pero no explican la escisión de los dialectos más septentrionales. Una hipótesis de trabajo podría partir de la tendencia arcaica del catalán occidental frente al carácter más avanzado en su evolución del catalán oriental: compárense $a, e$ átonas diferencias, nasales mantenidas en antiguos esdrújulos (hòmens), desinencias de Subjuntivo presente en - $a$, -es, - e, - en, la - $d$ - no vocalizada de hedra, etcétera, del occidental, frente a $a, e$ confundidas en $/ \partial /$, la nasal perdida (homes), desinencias en $-i,-i s,-i,-i n$, vocalización de $-d-$ en $/ \mu /$, etcétera, del oriental, respectivamente (cf. Veny, $1978 a$ ). Habría que intentar también un estudio interdisciplinario que pusiera en relación el mapa dialectal con el mapa genético (como se ha hecho para Cerdeña, cf. Contini, 1988-1989) para constatar coincidencias y discordancias y sacar de ello conclusiones. De todas formas, se han registrado reticencias hacia la bipartición oriental/occidental (Viaplana, 1985 y De Cesaris, 1986); basándose en tendencias fonéticas de los dialectos actuales, Recasens (1992) ha encontrado afinidades entre ellos en un sentido diferente al de la división tradicional. Tal profusión de propuestas hace pensar en el carácter notablemente convencional de estas divisiones, ya que los resultados cambian según el sector lingüístico considerado, la selección de los fenómenos, su consideración sincrónica o diacrónica. A pesar de todo, continúo pensando que la división de Milà, como macrodivisión asentada en criterios descriptivos y que a menudo viene vertebrada en raíces históricas, sigue teniendo vigencia.

La geolinguística debe ir más allá de los atlas regionales preparando microatlas de ciertas áreas dialectales, especialmente las áreas de transición, o de carácter temático monográfico sobre fonética, morfología, léxico (las setas, los pájaros, los peces, 1a indumentaria, etcétera). 
La ampliación territorial de los atlas permite constatar los elementos comunes y diferenciales en relación a otras lenguas, románicas (ALIR) o europeas (ALE); así, el cat. jove "nuera" se muestra como una innovación semántica singuiar en el conjunto europeo. Ese tipo de atlas así como la yuxtaposición de atlas de dominios vecinos hace posible detectar préstamos y, ayudados de la documentación, distinguirlos de los casos de continuidad de área lingüística, propios de los dominios de dialectos constitutivos: el cat. norteoccidental navalla "navaja" es un caso de continuidad de área linguística mientras que lligallo "cañada, camino de cabaña" constituye un préstamo aragonés (Veny, 1991). Esos fenómenos, a menudo difíciles de separar, se encuentran al Norte, en rosellonés, y al Oeste, en catalán norteoccidental, de Tamarit hacia el Norte.

4. Eso nos lleva de la mano al contacto de lenguas, tema muy productivo entre nosotros, puesto que el catalán presenta contactos con el castellano (de la frontera política con Francia hasta el Sur del dominio), con el francés (Rosellón) y con el italiano (Alguer [Cerdeña]). La interferencia provoca numerosos casos de hipodiferenciación, de hiperdiferenciación, de reorganización del sistema, de pérdidas, de importaciones, de sustituciones (Payrató, 1985). He aquí un tema que participa de la sociolingüística y que se muestra atractivo y grávido de posibilidades.

Lo que ha provocado este contacto de lenguas, en el territorio políticamente español, ha sido no sólo la oficialidad de esta lengua, con todas sus consecuencias (medios de comunicación, escolarización, cine, administración, etcétera), sino también la enorme masa de inmigrantes alóglotos llegados sobre todo después de la guerra civil (1936-1939), ya que antes, por su número más reducido, eran objeto de asimilación. Con el restablecimiento de la democracia (1975) y la instauración de la autonomía, con la aprobación de los estatutos de autonomía (Cataluña [1979], Comunidad Valenciana [1982], Baleares [1983]), que declaran el catalán lengua oficial y propia de las mencionadas Comunidades, se van recuperando, en grado diverso, los espacios que el castellano había ocupado; la política linguiística del gobierno autónomo de Cataluña se esfuerza por difundir el conocimiento del catalán, también entre los hispanohablantes, así como el uso social del mismo; un grupo de profesionales de la comunicación defiende, como lengua estándar, un modelo alejado de una concepción cultural y humanística, más cercano al registro coloquial del catalán central, con rechazo de palabras consideradas arcaísmos (cercar sustituido por buscar, enguany por aquest any, etcétera) - pero que son vivas en los dialectos - y con aceptación de ciertos castellanismos (barco en vez de vaixell, guapo en vez de bell, formós, etcétera).

\section{LA CULTURA POPULAR}

5. Desde el final del siglo pasado hasta el presente, se abre ante nosotros un amplio abanico de producciones, aunque de valor desigual. Fue el archidu- 
que Lluís Salvador, con Die Balearen (1869-1891), tesoro de la cultura material y espiritual de estas islas, el precursor del movimiento Wörter und Sachen desarrollado en Alemania. Con la publicación de las Rondayes de Mallorca (1895), nos enseñó a publicar los materiales de literatura popular sin modificaciones, con toda fidelidad a los textos recogidos. Además de poder captar su valor folklórico en toda su integridad, una edición así presentada permite llevar a cabo estudios de carácter linguístico entre los que convendría dinamizar los de sintaxis, verdadera cenicienta de la investigación dialectológica. La serie de narraciones recogida en Rupit y Pruit (les Guilleries) por el Grup de Recerca Folklòrica d'Osona (1984) constituyen un modelo digno de ser imitado.

La etnolinguística ha enriquecido la dialectología con los nuevos métodos de la antropología, la sociolingüística y la semántica moderna. El estudio de Núria Vilà (1991) sobre las herramientas agrícolas del "Baix Camp" (Tarragona) ha abierto entre nosotros un nuevo campo de trabajo que ofrece perspectivas atrayentes.

La pragmática, por otro lado, ha visto aplicar sus principios a las adivinanzas (M. M. Bassols, 1989) y a la paremiología (Maria Conca, 1987) con cierta fortuna. En cambio, la aplicación del formalismo a la clasificación de las paremias en otras lenguas (por ejemplo, Berruto, 1972) no parece que haya encontrado una vía cómoda.

Formando parte del análisis del discurso, el registro coloquial (el catalán coloquial) se ocupa de la lengua en su manifestación cotidiana, espontánea, oral e informal; comprende el estudio de las interferencias, de los cambios de código, de la mezcla de códigos, de los registros simplificados, de los tabúes, de los gestos, etcétera (Payrató, 1988). En rigor, no existe un catalán coloquial sino que cada dialecto tiene un registro coloquial. Su estudio participa de la dialectología, pero superándola gracias a su recurso a la pragmática y a la sociolingüística. He aquí otra rama de la dialectología que puede dar frutos renovados.

\section{DIALECTOLOGÍA FILOLÓGICA}

6. La homogeneidad de la lengua medieval catalana atrajo la atención de los investigadores, especialmente extranjeros, puesto que esta situación contrasta con la heterogeneidad dialectal de la "langue d'oil" o de las variedades italianas. Los dialectos existían, con diferencias menos estridentes que en otros dominios, pero no se encontraban manifestaciones escritas de estas diferencias a causa de la influencia niveladora de la cancillería; la extensión modesta de esta lengua y la presencia en ella de dialectos constitutivos y consecutivos contribuyó también a una fragmentación más suave. 
A pesar de ello, durante estos últimos decenios han visto la luz diversas obras que enriquecen el texto publicado con un estudio lingüístico que pone de relieve características dialectales antiguas; se trata de las contribuciones de Coromines (1943-1945) sobre el rosellonés del siglo XIII, de Veny (1971) sobre el norte-occidental del siglo XIV, de Miralles (1984) sobre el mallorquín del siglo XIV, de M. Dolors Farreny (1986) sobre el leridano del siglo XV. Los Llibres de Cort (o de Crims), el más fiel reflejo de la antigua lengua coloquial, son la fuente más importante para completar la formación de una dialectología diacrónica que ya se nos presenta sólida y madura. De esta manera se ha puesto de relieve la antiguiedad de ciertas isoglosas que separan el catalán occidental del catalán oriental (junc/jonc, hedra/heura, llangost/llagost, etcétera, Veny, 1978, b) o se han reforzado propuestas etimológicas con puntos de apoyo documentales (por ejemplo: pestriu "tipo de tiburón" procedente del lat. PRISTIS "bestia salvaje”, cruzado con PISTRIX "panadera", es el único derivado popular románico de esta palabra latina, de la que he encontrado testimonios de los siglos XIV y XVI; Veny, 1979). Subrayemos, a este propósito, el concurso de la onomástica para retrotraer la cronología de ciertas unidades léxicas o de algunos fenómenos fonéticos: así, la primera documentación de espígol "espliego" de 1409 retrocede a 1175 con un "Berengarii d'Espígol" y lo mismo en muchos otros casos (Veny, 1980).

Hay que ser prudentes a la hora de utilizar fuentes lexicográficas, puesto que la transfusión de palabras de un autor a otro resulta frecuente y existe el riesgo de una atribución dialectal falsa (Veny, 1986).

\section{FONÉTICA EXPERIMENTAL}

7. Es indiscutible que la fonética experimental ha conocido un progreso extraordinario durante esos últimos lustros. Los hechos dialectales fueron objeto de la atención de Pere Barnils, quien cimentó las bases de esta disciplina (Julià, 1992) (véase, por ejemplo, su estudio sobre las $/ k, g /$ mallorquinas palatalizadas [Barnils, 1915]). Pero es cierto que muchos sonidos y fenómenos de coarticulación deben ser examinados bajo nuevas perspectivas metodológicas, como lo han hecho J. Mascaró y J. Rafel (1982) a propósito de la (e) intervocálica balear de palabras como paia (cat. normativo palla "paja") < lat. PALEA. El inventario de temas a tratar es amplio: pueden ser ejemplos la $/ t /$ palatalizada tras yod (en vuit, por ejemplo), en una zona del norte-occidental, la cualidad diferente de la / $/$ / tónica de las Baleares, la cantidad de $/ a /$ / $<$ sufijo-ada) del valenciano, la $l$ mallorquina, la $/ e /$ final $(<-a)$ del leridano, la realización neutra de /a/ átona en ciertas hablas norteoccidentales, etcétera. Y sobre todo, la entonación. Ignasi Mascaró (1976) ha puesto una primera pie- 
dra con su estudio sobre las frases interrogativas en menorquín, pero sólo es un comienzo. Es urgente profundizar en este campo antes que el bilingüismo y la influencia de la lengua estándar enturbien las características más puras de nuestros dialectos. ¿No sería posible una clasificación dialectal según la entonación?

\section{SOCIODIALECTOLOGÍA}

8. Entre las últimas corrientes de la lingüística, el estructuralismo ha contribuido a ciertos progresos como el de poner orden en los conceptos de fonema y realización fonética, el recurso al diasistema para comparar dialectos o la presentación de léxico en campos semánticos. La pragmática ha dado sus frutos por lo que se refiere a la lengua coloquial y la cultura popular, como también la etnolingüística en relación con esta última (cf. $\Omega$ 5). La gramática generativa, centrada en el análisis de la lengua normativa o común, ha abierto algún portillo dialectal (por ejemplo, Colomina, 1985, que se ha ocupado del valenciano meridional alicantino), pero esperamos más ensayos y aplicaciones para juzgar objetivamente de la bondad de sus resultados.

Ahora bien, el método que ha contribuido más a dar nueva savia a la dialectología ha sido sin duda la sociolinguística. ¿Sería abusivo llamar Sociodialectología a la aplicación de los principios de la sociolinguística a los datos dialectales? A la diferencia geográfica, hay que añadir la diferencia social según variables de edad, sexo, instrucción, clase social, de las que se han escogido muestras representativas. Muchos problemas de variación actualmente no se pueden abordar si no es bajo esta perspectiva; por ejemplo, es inexacto decir que en una gran parte del catalán central se practica la "yodización", puesto que existe una buena parte de hablantes que no la conocen o que la practican parcialmente de acuerdo con variables de edad, sexo, etcétera; se trata de una articulación que se bate en retirada a causa de la presión de la lengua escrita, del modelo estándar, del barcelonés (que se sirven de la $/ \lambda /$ ), etcétera, que han hecho subestimar la pronunciación yeísta; por medio del método sociolingüístico (Bau-Font, 1992; Pons, 1988 y Cassany 1983), se puede seguir de cerca el laborioso proceso de substitución.

Muchos fenómenos dialectales pueden estudiarse a la luz de este método: la alternancia $/ \mathrm{d} 3 /-/ t / /$ (del tipo viatge/viatxe "viaje"), o de $/ / /-/ t] /$ (del tipo ràfec/tiàfec "chaparrón") en catalán oriental; la influencia niveladora de las hablas urbanas, especialmente Barcelona (como el caso de trumfa/patata, estudiado por Badia. 1979); las actitudes interdialectales (como las analizadas 
por Pueyo, 1980), las actitudes metalingüísticas (tenemos una muestra en Veny 1985); la elección de formas dialectales o estándar en actos formales de habla (sirve de modelo la contribución de Bibiloni [1983] sobre el mallorquín), etcétera. El contacto de lenguas se inscribe también dentro de este programa de trabajo tan atractivo.

\section{RELACIÓN ENTRE DIALECTOS Y LENGUA ESTÁNDAR}

9. Casi todas las lenguas de cultura han basado su código estándar en un dialecto de los diversos que forman la lengua histórica o de diferenciación. Sin embargo, el catalán ofrece a este propósito una situación muy singular puesto que la alternativa de codificación ha sido de base composicional, con participación de los cuatro grandes dialectos. Fue Fabra, el cerebro de la nueva normativa, quien abrió este camino - que ya conocía precedentes-; y la Sección Filológica del "Institut d'Estudis Catalans", academia de la lengua, continúa trabajando — quizá con más rotundidad desde su reestructuración - sobre idénticos principios. Resulta de ello que, en el nivel fonético, no hay un dialecto que se erija en único modelo ortoépico, como ha ocurrido en francés, sino al contrario: se dinamizan las características más tradicionales y prestigiosas de cada gran comunidad dialectal, eliminando las formas consideradas vulgares, casteIlanizadas o demasiado locales; y se aplican dos criterios, uno, geográfico, que tiene en cuenta un espacio general o restringido, y otro de registro, más formal o menos formal; el espacio restringido y el registro menos formal permiten una más fuerte aproximación a las características más dialectales (IEC, 1990).

Sucede lo mismo en los otros sectores de la lengua, aunque la morfología, especialmente verbal, plantea problemas delicados. Por lo que se refiere al léxico, el corpus general viene constituido por palabras procedentes del catalán oriental, muchas de ellas de carácter común, pero los otros grandes dialectos (norte-occidental, valenciano, balear) participan también en el mismo; su conocimiento, actualmente más profundo, permite la incorporación más generosa de nuevas unidades dialectales de acuerdo con los criterios que se desprenden de la obra de Fabra (área geográfica, tradición documental, empleo literario, carácter denotativo, expresividad, etcétera).

He aquí cómo la dialectología asume en catalán un papel importante en la formación de la lengua literaria o estándar.

\section{CONSIDERACIONES FINALES}

10. ¿Dónde va la dialectología catalana? Parece que la realización de atlas de tipo tradicional, por lo que se refiere a su contenido léxico, será cada 
vez más difícil, en especial por el desvanecimiento y ocaso de muchos referentes rurales; en todo caso se elaborarán con un cuestionario modificado donde no faltarán las cuestiones sociolingüísticas (de actitudes, etcétera); a mi parecer, conviene emprender microatlas para estudiar las áreas de transición (como ya se ha hecho en parte) así como microatlas de temática monográfica (ornitonimia, ictionimia, etcétera), de carácter interdisciplinario. El tratamiento informático permitirá una explotación exhaustiva y sistemática de los materiales geolingüísticos (índice total de formas, sufijación, explotación fonética, morfológica y léxica, en forma de mapas, de una respuesta; etcétera). A los cultivadores de la fase interpretativa de los atlas les quedan muchos problemas pendientes para poner a prueba su intuición, sus conocimientos "culturales" y su vertiente humanística; únicamente deberán cambiar de método cuando éste se manifieste infructuoso, y no por simples imperativos de la moda.

La combinación de atlas de dominios vecinos, unida a la investigación etimológica, permitirá distinguir los préstamos de los casos de continuidad de área linguística, y aportar una nueva luz a los cambios semánticos a través del método comparativo.

No se debe renunciar a los estudios monográficos, allí donde la vitalidad del habla lo permita. Los dialectos, además de constituir sistemas cuya descripción meticulosa corresponde al análisis puntual, proporcionan con sus tendencias sea creativa sea arcaizante bellos ejemplos para la lingüística general y la linguí́stica histórica. Cada punto nuevo explorado trae consigo preciosas novedades para el dialectólogo.

La cultura popular, cuya fase de recogida de datos se ha hecho hoy menos fructuosa que ayer, se enriquece con las aportaciones de la etnolingüística y de la pragmática. La lengua coloquial, estudiada en el marco del análisis del discurso, of rece materiales más vivos que los de ciertos dialectos y, en todo caso, de un interés diferente. Por otra parte, la descripción tipológica de los gestos, aplicada con fortuna al catalán central (Payrató, 1989), ofrecerá el interés de cierta variación si se extiende a otros dominios lingüísticos.

Deberían intensificarse las ediciones esmeradas de textos antiguos, especialmente no literarios, medievales y postmedievales, para hacer avanzar la dialectología diacrónica y facilitar la investigación etimológica, comprendida como historia de las palabras; la onomástica será — tiene que ser - su valioso complemento.

La fonética experimental debería ampliar más su campo de estudio a los problemas dialectales; la entonación tendría que ser un tema prioritario.

Teniendo en cuenta la relación entre pedagogía y área dialectal, se ha de reconocer la necesidad del conocimiento de ésta para sacar mejor partido de aquélla en especial en los primeros ciclos de la enseñanza. M. Dolors de Ribot 
(1992) ha abierto un camino con su estudio sobre la adquisición del sistema fonológico en la población infantil de las comarcas gerundenses.

La búsqueda de un soporte teórico no ha de estar ausente de los objetivos dialectológicos. Empirismo y teoría tienen que darse la mano para enriquecerse mutuamente.

El método sociolinguístico se ha mostrado eficaz para el estudio del proceso de cambio, con toda su complejidad en nuestros dialectos. No se puede olvidar esta vertiente. Incluso pensando en el futuro profesional, ya que, cuando los dialectos horizontales hayan desaparecido - ¿realmente van a desaparecer?-, nuestros dialectólogos, debidamente reconvertidos, podrán ocuparse de los dialectos verticales.

\section{BIBLIOGRAFIA}

ALAND = A.. Griera: Atlas Lingïístic d'Andorra, Andorra, 1960.

$\mathrm{ALC}=$ A. Griera: Atlas Lingüistic de Catalunya, 8 vols., Barcelona, 1923-1964.

Alcover, A. M., y Moll, F. de B. (1929-1933): La flexió verbal en els dialectes catalans, Publicacions de l'Oficina Romànica, Barcelona.

ALDC = Atlas Lingüistic del Domini Català, Universidad de Barcelona e "Institut d'Estudis Catalans" (en curso de elaboración).

ALE= ALINEI et alii: Atlas Linguarum Europae, I, 2 fasc., Assen, 1983-1986.

ALF: = GILLIÉRON, J.: Atlas Linguistique de la France, París, 1902-1910.

ALIR= CoNTIN, M. et ali: Atlas Linguistique Roman, Grenoble (en curso de elaboración).

ALPI= Atlas Lingüístico de la Península lbérica, I, Madrid, 1962.

ALPO = GutTs: H.: Atlas Linguistique des Pyrénées Orientales, París, 1966.

Al.arcos, Emilio (1960): La constitución del vocalismo catalán, "Studia Philologica. Homenaje ofrecido a Dámaso Alonso por sus amigos y discípulos con ocasión de su 60 aniversario". I (Madrid), 35-49.

Atlas Sacase $=$ Cost A, G. J. (1986): Atlas Linguistique "Sacaze" des confins catalanolanguedociens, $\mathrm{I}$, Barcelona.

BADIA Margarit, A. (1979): «Sobre el procés d’anivellament del vocabulari rural català. Presentació i comentari d'un cas concret». Hommage à Jean Séguy (Toulouse), I, 99 120. 
ID. (1981): La formació de la llengua catalana, Montserrat.

Barnils, Pere (1915): «L'articulació de la K i la G mallorquines», Butlleti de Dialectologia Catalana, III, 73-79 (y en Anuari de l'Oficina Romànica de Lingüistica i Literatura, VI, 1933, 51-57).

Bassols, Maria M. (1989): Anàlisi pragmàtica de les endevinalles catalanes, tesis doctoral, Universidad de Barcelona.

Bat, Imma, y Font, Ramona (1991): La iodizació a la Plana de Vic, "Actes del II Congrés Internacional de la Llengua Catalana" (en prensa).

Berrl.TO, G. (1972): «Significato e strutture del significante in testi paremiografici» Parole e metodi, Torino, 4, 189-211.

BIBILon, Gabriel (1983): La llengua dels mallorquins. Anàlisi sociolingüistica, tesis doctoral, Universidad de Barcelona.

CABrÉ, M. Teresa (1977), «Delimitació de la frontera català oriental-català occidental en la zona de l'Argentera-la Torre de Fontaubella-Capçanes», Anuario de Filología (Universidad de Barcelona), III, 445-456.

CASSANY, Jordi (1983): "Notes sobre el "ieisme" a la comarca d'Osona", Ausa (Vic), $\mathrm{XI} / 106-107,93-104$.

Conca, María (1987): Paremiologia, Universidad de Valencia.

Contıni, M., et alii (1988-1989): «Géolinguistique et géogénétique: une démarche interdisciplinaire», Géolinguistique, IV, 129-197.

COl_ominas, Jordi (1985): L'alacanti. Un estudi sobre la variació lingüistica. Alacant.

Corominas, J. (1943-1945): «Las Vidas de Santos rosellonesas del manuscrito 44 de París», Anales del Instituto de Lingüística de la Universidad de Cuyo, Mendoza. III, 126-211.

DECESARIS, Janet (1986): «Les divisions dialectals del català», Actés del VII Colloqui Internacional de Llengua i Literatura Catalanes, Montserrat, 679-701.

Farreny, M. Dolors (1986): Processos de crims del segle XV a Lleida: transcripció $i$ estudi lingüistic, Lleida.

Ferrando, Antoni (1989): La formació historica del català, «Segon Congrés Internacional de la Llengua Catalana. Area 7. Historia de la Llengua», València, 399428.

GRilRA, Antoni (1914): La frontera catalano-aragonesa, Barcelona.

Grup de Recerca Folklórica Dosona (1984): El folklore de Rupit i Pruit. II. Narraciones, Vic.

ID (1931): Gramàtica històrica del català antic, Barcelona. 
GuITER, H. (1973): "Atlas et frontières linguistiques", Les dialectes romans de France à la lumière des atlas régionaux, Paris, 62-109.

HADWIGER, J. (1905): «Sprachgrenzen und Grenzmundarten des Valencianischen», Zeitschrift für Romanische Philologie, 712-731.

Haensch, G. (1960): Las hablas de la Alta Ribagorza (Pirineo Aragonés), Zaragoza.

ICE $(1990)=$ Institut d'Estudis Catalans. Secció Filològica: Proposta per a un estàndard oral de la llengua catalana. I. Fonètica, Barcelona.

JuLIÀ, Joan (1992): Pere Barnils (1882-1933): l'home i el lingüista, Barcelona (en prensa).

KRÜGER, F. (1913): Sprachgeographische Untersuchungen in Languedoc und Roussillon, Hamburg (y en Revue de Dialectologie Romane. III, 1911, y v., 1913).

Mascarò, Joan, y RAFFL, Joaquim (1982): «La e intervocálica baleàrica», Randa (Barcelona), 11, 37-44.

MEnÉndez PidAl, R. (1916): Recención de A. GRIERA, «La frontera catalano-aragonesa», Revista de Filología Española, III, 73-88.

Milà I Fontanals, M. (1961): «De los trovadores en España», Barcelona, 462-464.

Miralles, Joan (1984): Un llibre de cort reial mallorqui del segle XIV (1357-60). Introducció, transcripció i estudi lingüistic, Mallorca.

Payrató, Lluís (1988): Català col.loquial Aspectes de l'ús corrent de la llengua catalana, Universidad de Valenci

Payrató, Lluís (1989): Assaig de dialectologia gestual. Aproximació pragmàtica al repertori bàsic d'emblemes del català de Barcelona, tesis doctoral, Universidad de Barcelona.

ID (1985): La interferència lingüistica, Montserrat POLANCO. (1984), Llengua i dialectes: una aplicació dialectomètrica a la llengua catalana, Miscellània Sanchis Guarner. València, 267-276.

Pons, Lídia (1988): Dos fenòmens fònics a Barberà del Vallès, tesis doctoral, Universidad de Barcelona (en prensa).

Pueyo, M. (1980): «Vikings i pagesos: una batussa continuada. Assaig per a un estudi de les relacions interdialectals en català», Treballs de Sociolingüística catalana, III, 83102.

RAFEl., J. (1981): La lengua catalana fronteriza en el Bajo Aragón meridional. Estudio fonológico, Universidad de Barcelona.

I1) (1977): «Consideraciones léxico-semánticas a partir de una investigación exhaustiva (Bajo Aragón meridional de habla catalana)», Revista Española de Lingüística. VII, $137-170$. 
RECASENS, D. (1985): Estudi lingüístic sobre la parla del Camp de Tarragona, Montserrat.

ID (1991): «Tendències fonètiques i classificació dialectal al domini lingüístic català», Llengua i Literatura. Revista anual de la Societat Catalana de Llengua i Literatura, Barcelona, 4.

Riвot, M. Dolors de (1992): Problemàtica del sistema fonemàtic de la llengua catalana a les comarques de Girona, Montserrat, 1992.

Salow, K. (1912): Sprachgeographische Untersuchungen üher den östlichen Teil des katalanisch-langedokischen Grenzgebietes, Hamburg.

Sanchis Guarntr, M. (1956): «Factores históricos de los dialectos catalanes», Estudios dedicados a Menéndez Pidal, VI, 151-186.

SARdÁ, A., y Gutter, H. (1975): «L'“Atlas Lingüístic de Catalunya” i la fragmentació dialectal del català», Miscellania Barcinonensia (Barcelona), XL. 93-112.

SARDÁ, A. (1977): «Le mythe du dialecte roussillonnais», Revue de Linguistique Romane, $41,154-161$.

SAPON, S. M. (1957): A Pictorial Linguistic Interview Manual (PLIM), The Ohio State University, Columbus (Ohio).

SchädEL, B. (1908): «La frontière entre le gascon et le catalan», Romania, XXXVII, 140156.

SISTAC, R. (1987): El ribagorçà a l'Alta Llitera. Els parlars de la Vall de la Sosa de Peralta, tesis doctoral, Universidad de Barcelona (en prensa).

VENY, Joan (1971):Regiment de preservació de pestilència, de Jacme d'Agramont (s. XIV). Introducció, transcripció i estudi lingüístic, Diputació de Tarragona.

I1) (1978 a): Els parlars, Barcelona (3. ${ }^{a}$ ed., Els parlars catalans, Palma de Mallorca, 1982).

ID (1978 b): Estudis de geolingüistica catalana, Barcelona.

ID) (1979): «De la bèl.lua al tauró: supervivents catalans del llatí "pistrix"», Randa (Barcelona), 9, 51-62.

ID (1980): »Antroponímia i lingüística diacrònica». Societat d'Onomàstica. Butlletí interio, I, 38-39.

ID (1985): «Actituds metalingüístiques en textos dialectals». Actes del I Col.loqui sobre les Fonts Orals, Monestir de la Real (inédito; hay un resumen en Veny 1986, 207$210)$.

ID (1986): Introducció a la dialectologia catalana, Barcelona. 
ID (1988): Noves dades sobre la partió català occidental-català oriental, "Actes del Cinquè Col.loqui d'Estudis Catalans a Nord-Amèrica (Tampa-St. Augustine, 1987)"” a cura de Ph. D. Rasico i C. J. Wittlin, Montserrat, 11-4l.

ViaPlaNa, J. (1985): «En relació a la distinció oriental-occidental. Notes crítiques sobre el mapa dialectal del català», Miscel.lània Badia, Montserrat, 2, 27-36.

VILÀ, Núria (1991): «Estudi del vocabulari de les eines agrícoles a la comarca del Baix Camp», IEC, Barcelona. 